\title{
The Long-Term Prognostic Value of Bone Scintigraphy in Legg-Calvé-Perthes Disease
}

\author{
Marcus Vinicius Moreira' ${ }^{1,2,3}$, Luciano S Dias ${ }^{4 *}$ and Luiz R A de Angeli ${ }^{3,5}$ \\ ${ }^{1}$ Pediatric Orthopedic Division, Association for the Care of Disabled Children, Sao Paulo, Brazil \\ ${ }^{2}$ Department of Orthopedics and Traumatology, Federal University of Sao Paulo (UNIFESP), Brazil \\ ${ }^{3}$ Hospital Israelita Albert Einstein, Sao Paulo, Brazil \\ ${ }^{4}$ Division of Orthopaedic Surgery, Ann \& Robert H. Lurie Children's Hospital of Chicago, Chicago, USA \\ ${ }^{5}$ Department of Orthopedics and Traumatology, University of Sao Paulo, Sao Paulo, Brazil
}

Submission: March 18, 2021; Published: March 29, 2021

*Corresponding author: Luciano S Dias, Division of Orthopaedic Surgery, Ann \& Robert H. Lurie Children’s Hospital of Chicago, Chicago, USA

\section{Abstract}

Purpose: Predicting the prognosis of Legg-Calvé-Perthes disease (LCPD) in its earlier stages is still a challenge. The purpose of this study is to evaluate the reliability of Conway's scintigraphic classification in a long-term follow-up cohort of patients with LCPD.

Methods: We reviewed the records of 44 consecutive patients diagnosed with LCPD at the Waldenström initial stage of the disease, who underwent serial bone scans and were treated conservatively. Patients were classified as Pathway A, B, or C, according to Conway's classification. The age at onset of symptoms and the Stulberg classification at skeletal maturity were analyzed.

Results: Of the 44 patients involved in this study, 31 were males and 13 were females. The average age at onset of symptoms was 5 years and 11 months, and the average follow-up time was 13.6 years (range, 9.2 to 20.7). Two patients had both hips affected. Thus, for a total of 46 hips, 33 were classified in Pathway A and 13 were classified in Pathway B. Group A had 81.8\% good results (Stulberg I and II), and 18.2\% had poor results (Stulberg III and IV). Group B had $23.1 \%$ good results and $76.9 \%$ had poor results. These results were statistically significant (P < 0.001 ). No Stulberg 5 hip was seen. The age of onset of symptoms did not correlate with the final outcome $(P=0,09)$.

Conclusion: Bone scintigraphy is a reliable and valuable tool in predicting long-term outcomes at the early stage of LCPD in patients below the age of 8 years.

Level of evidence: Level II - prognostic study.

\section{Introduction}

Predicting the prognosis of Legg-Calvé-Perthes disease (LCPD) in its earlier stages is still a challenge. The long-term outcome can be a normal joint or arthritis secondary to the epiphyseal deformity and hip incongruity [1]. It is known that the chances of retaining a spherical femoral head increase if the treatment is implemented in the early stages of the disease [2]. However, the most reliable radiographic prognostic classifications systems can only be correctly applied in the late fragmentation phase [3-7]. Thus, there has been an increasing interest in other imaging methods to try to predict prognosis before the radiographic changes become advanced [8]. Currently, Magnetic Resonance Imaging (MRI) is the most used method for this purpose. The vascularity assessment of the proximal femoral epiphysis in the early stages of LCPD is better done with advanced MRI techniques, such as the dynamic gadolinium-enhanced subtraction (DGS) MRI, also known as perfusion MRI, and the diffusion-weighted imaging (DWI) MRI [8-13]. Both have demonstrated a good prognostic value in the short term follow-up [11,14-17]. However, despite the progress that has been made in this area, there are still no prognostic classifications or treatment recommendations derived from these investigations [8].

The first attempts to visualize bone revascularization patterns and to predict prognosis in the early stages of the disease were done using bone scintigraphy in the early 1980s, by Conway and Bensahel et al. [18-20]. In 1993, Conway described a fourstage classification based on the revascularization pattern of the femoral head [21]. This classification divided the revascularization patterns into three groups: Pathway A (Figure 1), Pathway B (Figure 2) and Regression group, also known as Pathway C [21,22]. Basically, Pathway A correlates with early revascularization and 
the appearance of a lateral column in stage IIA, which indicates a better prognosis. Pathway B, though, correlates with delayed revascularization and a base-filling pattern in stage IIB, which indicates a worse prognosis. Last, the Regression pattern refers to a change in the revascularization from Pathway A to B, also indicating a worse prognosis. In 1997, Tsao et al. demonstrated that Conway's classification had an important prognostic value [22]. Studies using advanced MRI techniques have shown revascularization patterns that are similar to the ones described by Conway $[10,23]$.
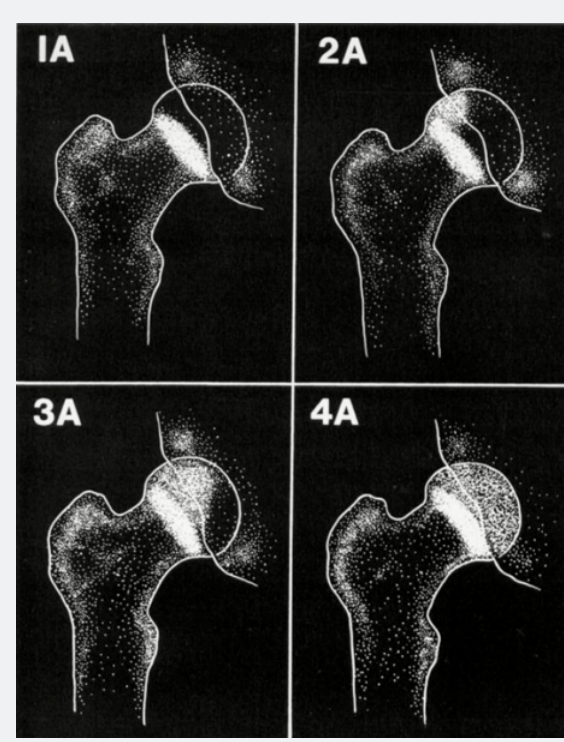

Figure 1: Pathway A: diagrammatic representation of scintigraphic images of the right hip. Stage $1 \mathrm{~A}$ (whole head involvement): the entire epiphysis is devoid of scintigraphic activity. Stage 2A (lateral column): a distinct column of scintigraphic activity is seen in the posterolateral portion of the femoral epiphysis in the anterior projection. Stage 3A (medial extension): The lateral column of activity observed in Stage $2 \mathrm{~A}$ is present and, in addition, the scintigraphic activity has extended medially in the anterior projection and anteriorly in the frog-leg lateral projection. Stage 4A (complete revascularization): scintigraphic activity is demonstrated throughout the entire epiphysis (reproduced with permission from Luciano S Dias).

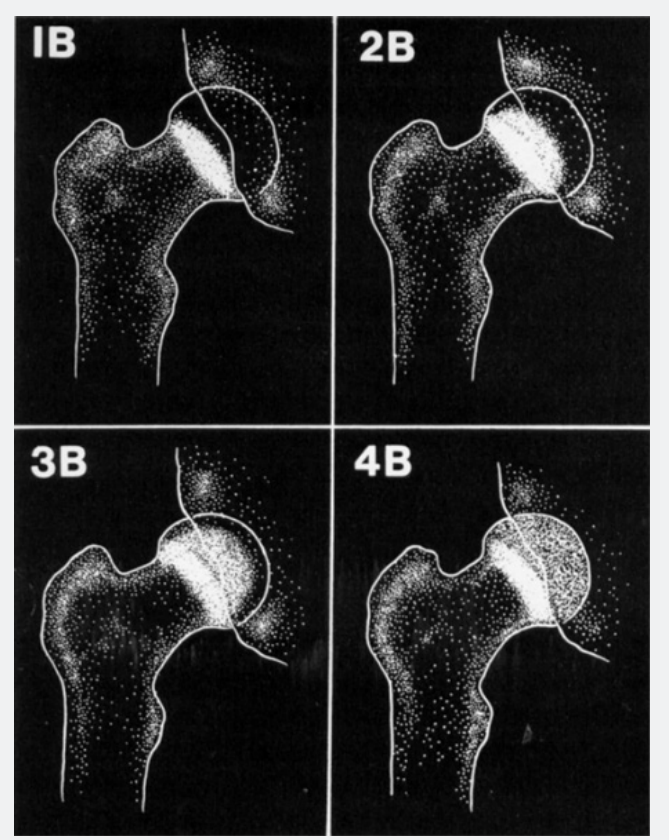

Figure 2: Pathway B: diagrammatic representation of scintigraphic images of the right hip. Stage 1B (whole head involvement): the entire epiphysis is devoid of scintigraphic activity. Stage 2B (base filling): the scintigraphic activity extends centrally. The lateral column is absent. Stage 3B (mushroom): scintigraphic activity involves one half of the epiphysis in the anterior and frog-leg view. Stage 4B (complete revascularization): scintigraphic activity is demonstrated throughout the entire epiphysis (reproduced with permission from Luciano $\mathrm{S}$ Dias). 
Although bone scintigraphy and advanced MRI techniques have shown a good prognostic value, to date, there are still no studies about their long-term assessment in LCPD. Thus, the purpose of this study is to evaluate the reliability of Conway's scintigraphic classification [21,22] in a long-term follow-up cohort of patients with LCPD, who underwent conservative treatment.

\section{Materials and Methods}

This protocol was approved by the Institutional Review Board and was in compliance with the Helsinki declaration. From 1993 to 2004, we reviewed the records of 44 consecutive patients diagnosed with LCPD at the initial stage (or necrosis stage) according to the Waldenström classification [24,25] who were submitted to serial bone scintigraphic studies and were treated conservatively. Patients who had surgery were excluded from this study. All patients were followed until skeletal maturity by the senior author. The age at onset of symptoms and the Stulberg classification [1] in the last follow-up radiographs were analyzed.

All patients underwent conservative treatment, which included: medication for pain control, rest, avoiding running and jumping sports, and partial weight-bearing during the stages when the patient has shown a decreased range of motion and pain. Serial bone scans with pinhole magnification and pelvis plain radiographs were done at 3 to 4 -month intervals. The first scintigraphic study was done at the initial presentation, and the subsequent ones were obtained until the definition of one Pathway pattern (Figures 1 \& 2). Usually, 4 bone scans were sufficient to achieve this objective. The acquisition technique and safety of the procedure were previously reported [22].
The last radiographic study was then classified using the Stulberg classification [1]. Three types of congruency were then defined: (1) spherical congruency, types I and II; (2) aspherical congruency, types III and IV; and (3) aspherical incongruency, type V.

\section{Statistical Analysis}

For the purpose of statistical analysis, a comparative study among the Stulberg classified groups was made by using the Fisher test. The analysis of the age of onset of symptoms, in comparison with Conway's scintigraphic classification and Stulberg classification, was done using the Kruskal-Wallis test. The significance level was $5 \%$.

\section{Results}

Of the 44 patients involved in this study, 31 were males and 13 were females. Two patients had both hips affected. Thus, for a total of 46 hips, we analyzed 28 left hips and 18 right hips. The average age at onset of symptoms was 5 years and 11 months, ranging between 2 years and 8 months to 10 years and 2 months. The average follow-up time was 13.6 years (range, 9.2 to 20.7). All patients included were at the initial stage $[24,25]$. - or necrosis stage - of the disease when the first bone scintigraphy was done. According to the visualized bone scan pattern, patients were divided in 2 groups: Pathway A or Pathway B. In this study, none of the subjects were classified as Pathway C. The average age at onset of symptoms for Pathway A was 5 years and 11 months, and for Pathway B was 5 years and 10 months. Both groups were similar regarding the age at onset of symptoms $(\mathrm{P}=0.866)$ (Table 1).

Table 1: Age comparison between Pathways A and B.

\begin{tabular}{|c|c|c|c|c|c|c|}
\hline Pathway & Mean & S.D. & Median & Minimum & Maximum & $\boldsymbol{P}$ \\
\hline A & 5,99 & 2,01 & 6,08 & 3,17 & 10,17 & 0,866 \\
\hline B & 5,88 & 1,63 & 6,50 & 2,67 & 7,83 & \\
\hline
\end{tabular}

S.D: Standard Deviation

Of the 46 hips involved in the final analysis, 33 were classified in Pathway A and 13 were classified in Pathway B. The final Stulberg classification for Pathways A and B is demonstrated in Table 2. Group A had $81.8 \%$ good results (Stulberg I and II), and $18.2 \%$ had poor results (Stulberg III and IV). Group B had 23.1\%

Table 2: Outcome comparison between patients included in Pathways A and B.

\begin{tabular}{|c|c|c|c|c|c|}
\hline Pathway & I & II & III & IV & P \\
\hline A & $5(15,2 \%)$ & $22(66,6 \%)$ & $5(15,2 \%)$ & $1(3,0 \%)$ & $<0,001$ \\
\hline B & $1(7,7 \%)$ & $2(15,3 \%)$ & $4(30,8 \%)$ & $6(46,2 \%)$ & \\
\hline
\end{tabular}

good results and $76.9 \%$ had poor results. These results were statistically significant $(\mathrm{P}<0.001)$. No Stulberg 5 hip was seen. The age at onset of symptoms did not correlate with the final outcome (P = 0,09) (Table 3). 
Table 3: Patient's age mean and S.D., according to Stulberg classification and Pathways.

\begin{tabular}{|c|c|c|c|}
\hline Pathway & I - II & III - IV \\
\hline A & $5,79 \pm 2,03$ & $6,92 \pm 1,80$ & 0,090 \\
\hline B & $4,00 \pm 1,47$ & $6,58 \pm 1,05$ \\
\hline
\end{tabular}

S.D: Standard Deviation

The poor results in Pathway A included 6 patients with an average age at onset of symptoms of 6 years and 11 months. The single Stulberg 4 in this group was 8 years and 9 months old at the onset of symptoms. Furthermore, there were only 3 patients with good results in Pathway B, which presented with an average age at onset of symptoms of 4 years (Table 2).

\section{Discussion}

The vascular origin for LCPD has been reported by several authors [18-20,22]. Avascularity patterns of the femoral head with subsequent necrosis and bone resorption are present during the initial stages of the disease and are followed by reparative steps including revascularization and reconstitution of the bony structure $[19,20,22]$. In this healing phase, the balance between the new bone formation and the mechanical forces on the hip defines whether the patient will develop a structural deformity. A rapid rate of healing should prevent the occurrence of microfractures, collapse, and subluxation, which will lead to the ultimate femoral head bone deformity.

Radiographic classifications have been developed in an attempt to document changes during the disease evolution and their relationship with the outcomes [5-7,26,27]. These classifications can only be correctly used in the late fragmentation stage, which takes about 11 months to be visualized after the onset of symptoms [3]. Unfortunately, at this point, the femoral head collapse is too advanced to allow proper treatment $[2,3,8]$. Kelly et al. [28] demonstrated that the Catterall classification could not be accurately applied for an average of 8.1 months after the onset of the disease. Lappin et al. [29] demonstrated that 75\% of Herring grade A cases and $30 \%$ of Herring grade B required upgrading, only being confirmed with an average of 7 months after the onset of the symptoms. Bone scintigraphy has high accuracy in detecting vascular changes during the early stages of LCPD, and its prognostic value was well demonstrated by Tsao et al. [22]

This particular study [22] was the first one to evaluate the prognosis of LCPD using an imaging method during the initial stages [3]. With an average follow-up time of 4.4 years, Conway's classification was correlated with the Catterall classification, the presence of head-at-risk signs, and the Mose score $[4,30]$. The results showed that patients included in Pathway A had significantly better results according to the Mose score and the hip range-of-motion. No head-at-risk signs were seen in this group, which was also correlated with a better overall Catterall classification. Furthermore, Tsao et al. [22] demonstrated that the average time to identify children who progressed to Pathway A was 4.6 months after the onset of symptoms. According to Joseph et al. [3], the late fragmentation stage can only be identified approximately 11 months after the onset of symptoms, so that the radiographic classifications can be correctly applied. Consequently, Conway's classification might be able to predict the prognosis of the LCPD up to 6 months earlier than conventional radiographs, allowing faster decision-making regarding management.

In our study, the average follow-up time was 13.6 years. Patients included in pathway A (33 patients) had $81.8 \%$ good results (Stulberg I and II). Those who presented poor results (Stulberg III and IV) showed an average age at onset higher than the entire cohort. Patients included in pathway B (13 patients) presented $76,9 \%$ of poor results and only 3 patients had good outcomes, and their average age at onset was lower than that of the entire cohort (Table 2). These findings suggest that the age at onset might play an independent role in the disease outcome, regardless of the avascularity index or the revascularization pattern. Even though we did not find a statistically significant correlation of the age at onset with the final Stulberg classification (Table 3), further investigation with larger cohorts and advanced imaging methods applied in the initial stages of the disease may confirm this hypothesis in the future.

Our study has several strengths. To the best of our knowledge, this is the first study to show the long-term follow-up prognostic value of an advanced imaging method classification system applied in the initial stage of LCPD. Previous bone scan investigations showed the short-term correlation of the revascularization patterns with several radiographic classifications and outcome measures, but no long-term follow up study was further published [22,31-34]. Advanced MRI techniques still lack long-term followup studies. Previous reports showed a good correlation in the use of DGS and DWI images with the Herring classification and head deformity at a 2-year follow-up [11,14,15,17]. However, there's still no classification system derived from these MRI imaging methods ready to be applied in clinical practice. Another strength of this report is the homogeneity of our cohort, formed only by children diagnosed in the early stages of the disease and treated conservatively by the senior author, which decreases the possible bias generated by different treatment modalities in the outcomes. Lastly, our results are based in the Stulberg classification, which is, to date, the most reliable radiographic outcome measure in LCPD [1]. 
There are, still, some weaknesses in this study. First, its retrospective nature accounts for some limitations in data acquisition. Second, it lacks clinical data, which is important to completely understand the outcomes. We believe that if the hip range-of-motion, quality of life questionnaires, and gait analysis data could be gathered together, our study would be even more powerful. Third, it has a small sample size, which might underpower some of the statistical analysis done.

In conclusion, this study shows that serial bone scintigraphy is a reliable tool in predicting the long-term outcomes in young patients - below the age of 8 years - with LCPD. This approach provides more information during the early stages of the disease, allowing the pediatric orthopedic surgeon to make more effective interventions to alter the natural course of the disease, whenever needed [2-4].

\section{Compliance with Ethical Standards}

\section{Funding Statement}

No benefits in any form have been received or will be received from a commercial party related directly or indirectly to the subject of this article.

\section{Ethical Statement}

Ethical approval: All procedures performed in studies involving human partic-ipants were in accordance with the ethical standards of the institutional and/or national research committee and with the 1964 Helsinki declaration and its later amendments or comparable ethical standards.

Informed consent: Not required.

\section{Icmje Conflict of Interest Statement}

All authors declare that they have no conflict of interest.

\section{References}

1. Stulberg SD, Cooperman DR, Wallenstein R (1981) The natural history of Legg-Calve-Perthes disease. J Bone Jt Surg Am 63(7): 1095-1108.

2. Joseph B, Sreekumaran Nair N, Rao K L N, George Varghese, et al. (2003) Optimal timing for containment surgery for Perthes disease. J Pediatr Orthop 23(5): 601-606.

3. Joseph B, Varghese G, Mulpuri K, K L Narasimha Rao, N Sreekumaran Nair, et al. (2003) Natural evolution of Perthes disease: A study of 610 children under 12 years of age at disease onset. J Pediatr Orthop 23(5): 590-600.

4. Catterall A (1971) The natural history of Perthes' disease. J Bone Jt Surg - Ser B 53(1): 37-53.

5. Herring JA, Neustadt JB, Williams JJ, J S Early, R H Browne, et al. (1992) The lateral pillar classification of Legg-Calvé-Perthes disease. J Pediatr Orthop 12(2): 143-150.

6. Herring JA, Hui TK, Browne R (2004) Legg-Calvé-Perthes disease. Part II: Prospective multicenter study of the effect of treatment on outcome. J Bone Jt Surg - Ser A 86(10): 2121-2134.
7. Salter RB, Thompson GH (1984) Legg-Calve-Perthes disease. The prognostic significance of the subchondral fracture and a two-group classification of the femoral head involvement. J Bone Jt Surg Am 66(4): 479-489.

8. Laine JC, Martin BD, Novotny SA, Derek M Kelly (2018) Role of advanced imaging in the diagnosis and management of active LeggCalvé-Perthes disease. J Am Acad Orthop Surg 26(15): 526-536.

9. Kim HKW, Kaste S, Dempsey M, David Wilkes (2013) A comparison of non-contrast and contrast-enhanced MRI in the initial stage of LeggCalvé-Perthes disease. Pediatr Radiol 43(9): 1166-1173.

10. Kim HKW, Burgess J, Thoveson A, Paul Gudmundsson, Molly Dempsey, et al. (2016) Assessment of femoral head revascularization in leggcalve-perthes disease using serial perfusion MRI. J Bone Joint Surg Am 98(22): 1897-1904.

11. Yoo WJ, Kim YJ, Menezes NM, Jung-Eun Cheon, Diego Jaramillo (2011) Diffusion-weighted MRI reveals epiphyseal and metaphyseal abnormalities in Legg-Calvé-Perthes disease: A pilot study. Clin Orthop Relat Res 469(10): 2881-2888.

12. Boutault JR, Baunin C, Bérard E, D Labarre, C Domenech, et al. (2013) Diffusion MRI of the neck of the femur in Legg-Calve-Perthes disease: A preliminary study. Diagn Interv Imaging 94(1): 78-83.

13. Merlini L, Combescure C, De Rosa V, Mehrak Anooshiravani, Sylviane Hanquinet, et al. (2010) Diffusion-weighted imaging findings in Perthes disease with dynamic gadolinium-enhanced subtracted (DGS) MR correlation: A preliminary study. Pediatr Radiol 40(3): 318-325.

14. Yoo WJ, Choi IH, Cho TJ, Wooyoung Jang, Chin Youb Chung, et al. (2016) Risk Factors for Femoral head Deformity in the early stage of legg-calvé-Perthes Disease: MR Contrast Enhancement and Diffusion Indexes. Radiology 279(2): 562-570.

15. Kim HKW, Wiesman KD, Kulkarni V, Jamie Burgess, Elena Chen, et al (2014) Perfusion MRI in early stage of Legg-Calvé-Perthes disease to predict lateral pillar involvement: A preliminary study. J Bone Jt Surg Am Vol 96(14): 1152-1160.

16. Baunin C, Sanmartin-Viron D, Accadbled F, N Sans, J Vial, et al. (2014) Prognosis value of early diffusion MRI in Legg Perthes Calvé disease. Orthop Traumatol Surg Res 100(3): 317-321.

17. Du J, Lu A, Dempsey M, John A Herring, Harry K W Kim, et al. (2013) MR perfusion index as a quantitative method of evaluating epiphyseal perfusion in legg-calve-perthes disease and correlation with shortterm radiographic outcome: A preliminary study. J Pediatr Orthop 33(7): 707-713.

18. Bensahel H, Bok B, Cavailloles F (1983) Bone scintigraphy in Perthes disease. J Pediatr Orthop 3(3): 302-305.

19. Conway JJ, Weiss SC, Maldonado V (1983) Scintigraphic patterns in Legg-Calvé-Perthes disease. Radiology 149: 102.

20. Conway JJ (1986) Radionuclide bone scintigraphy in pediatric orthopedics. Pediatr Clin North Am 33(6): 1313-1334.

21. Conway JJ (1993) A scintigraphic classification of Legg-Calvé-Perthes disease. Semin Nucl Med 23(4): 274-295.

22. Tsao AK, Dias LS, Conway JJ, P Straka (1997) The prognostic value and significance of serial bone scintigraphy in Legg-Calve-Perthes disease. J Pediatr Orthop 17(2): 230-239.

23. Lamer S, Dorgeret S, Khairouni A, Keyvan Mazda, Pierre-Yves Brillet, et al. (2002) Femoral head vascularisation in Legg-Calvé-Perthes disease: Comparison of dynamic gadolinium-enhanced subtraction MRI with bone scintigraphy. Pediatr Radiol 32(8): 580-585. 
24. Canale ST, D’Anca AF, Cotler JM, H E Snedden (1972) Innominate osteotomy in Legg-Calvé-Perthes disease. J Bone Joint Surg Am 54(1): 25-40.

25. Waldenstrom H (1922) The Definite Form of the Coxa Plana. Acta radiol 57(7): e79-94

26. Hardcastle PH, Ross R, Hamalainen M, A mata (1980) Catterall Grouping of Perthes' Disease. An Assessment of Observer Error and Prognosis Using the Catterall Classification. J Bone Jt Surg Br 62-B(4): 428-431.

27. Gigante C, Frizziero P, Turra S (2002) Prognostic value of Catterall and Herring classification in Legg-Calvé-Perthes disease: Follow-up to skeletal maturity of 32 patients. J Pediatr Orthop 22(3): 345-349.

28. Kelly FB, Canale T, Jones RR (1980) Legg-Calve-Perthes disease. Longterm evaluation of non-containment treatment. J Bone Jt Surg - Ser A 62(3): 400-407.

29. Lappin K, Kealey D, Cosgrove A (2002) Herring classification: How useful is the initial radiograph? J Pediatr Orthop 22(4): 479-482.
30. Mose K (1980) Methods of measuring in Legg-Calve-Perthes disease with special regard to the prognosis. Clin Orthop Relat Res 150: 103109.

31. Van Campenhout A, Moens P, Fabry G (2006) Serial bone scintigraphy in Legg-Calvé-Perthes disease: Correlation with the Catterall and Herring classification. J Pediatr Orthop Part B 15(1): 6-10.

32. Neto LM, Dias L (1999) O uso da cintilografia óssea na doença de Perthes. Rev Bras Ortop 34(1): 14-20.

33. Kaniklides C, Sahlstedt B, Lönnerholm T, A Moberg (1996) Conventional radiography and bone scintigraphy in the prognostic evaluation of Legg-Calvé-Perthes disease. Acta radiol 37(4): 561-566.

34. Sankar WN, Lavalva SM, McGuire MF, Chanhee Jo, Jennifer C Laine, et al. (2019) Does early proximal femoral varus osteotomy shorten the duration of fragmentation in perthes disease? Lessons from a prospective multicenter cohort. J Pediatr Orthop 40(5): e322-e328.

\section{Your next submission with Juniper Publishers will reach you the below assets}

- Quality Editorial service

- Swift Peer Review

- Reprints availability

- E-prints Service

- Manuscript Podcast for convenient understanding

- Global attainment for your research

- Manuscript accessibility in different formats

( Pdf, E-pub, Full Text, Audio)

- Unceasing customer service

Track the below URL for one-step submission https://juniperpublishers.com/online-submission.php 